\title{
Revolutions in the Atlantic World: A Comparative History Wim Klooster
}

New York, New York University Press, 2009, 238 páginas, ISBN 978-0814747896

\section{RESEÑA \\ David Home \\ Valenzuela}

University of Florida, Florida, Estados

Unidos

dhome@ufl.edu

DOI

10.3232/RHI.2011.

V4.N1.09
En este conciso pero sugerente trabajo el historiador holandés Wim Klooster analiza los profundos cambios políticos y sociales generados por cuatro procesos históricos de la llamada Era de las Revoluciones. La Revolución Americana, la Revolución Francesa, la Independencia de Haití y la Independencia de Hispanoamérica son estudiadas desde una perspectiva comparada tratando de establecer relaciones, similitudes y diferencias que permitan entender de mejor forma las causas, desarrollos y consecuencias de estos episodios, todos ellos trascendentales en la transición del antiguo orden monárquico a la conformación y consolidación de estados nacionales soberanos en el mundo occidental. Si bien cada una de estas revoluciones ha recibido abundante atención historiográfica en forma independiente, el esfuerzo de Klooster resulta particularmente novedoso y útil tanto por analizarlas en conjunto, lo que amplía las posibilidades de análisis y comparación, como por incorporar el caso de Haití, hasta ahora descuidado desde este punto de vista.

El autor construye su obra sobre cuatro pilares fundamentales. En primer lugar, Klooster propone que cada una de estas revoluciones debe ser estudiada desde una perspectiva que le de especial relevancia a la situación política internacional del periodo. El clima de conflicto militar que caracterizó al mundo atlántico durante gran parte del siglo XVIII influyó en gran medida en los aires reformistas que propiciaron revoluciones de largo alcance ya que el financiamiento de las guerras trajo consigo una mayor presión sobre los contribuyentes, lo que generó descontento y movilización social a diferente escala. En segundo lugar, Klooster considera que ninguno de estos movimientos revolucionarios estaba predestinado a tener éxito; cada proceso, de acuerdo a sus particularidades, se gestó en medio de la incertidumbre por su desenlace y su resultado dependió de la evolución misma de los acontecimientos. En tercer lugar, el autor destaca el carácter de guerra civil que tuvieron la mayoría de estos conflictos armados. Las lealtades de los pueblos involucrados en ningún caso fueron unánimes hacia alguno de los bandos en disputa sino que más bien respondieron a motivaciones particulares y específicas que no siempre coincidieron con aquellas que movilizaban a las élites. Finalmente, Klooster 
cuestiona que la democracia haya sido el principal logro de la Era de las Revoluciones en el mundo occidental, como otros historiadores han sugerido. La democracia lejos de ser uno de los objetivos centrales de las revoluciones, se constituyó apenas en un subproducto de las mismas consolidándose solo en algunos de los casos estudiados.

Utilizando principalmente bibliografía de carácter secundario, el autor dedica un capítulo del libro a cada revolución, comenzando por un breve análisis interpretativo en el que menciona la significancia y trascendencia del proceso específico para luego dar paso a una descripción narrativa en la que aborda cronológicamente el desarrollo de los acontecimientos. En términos generales, Klooster propone que lo que une a las revoluciones estudiadas es la lucha contra los fueros y privilegios, disputa que adquiere formas y características distintas de acuerdo a cada caso revolucionario. Paradójicamente, el resultado de aquella lucha no siempre fue la constitución de sociedades más democráticas e igualitarias sino que en varios casos se tendió a la conformación de sociedades de marcado signo autoritario y con una notoria tendencia a la exclusión de determinados grupos sociales (negros, mulatos, indígenas, mujeres) en distinto grado y alcance.

Klooster es particularmente cuidadoso al proponer relaciones de causalidad directa entre los episodios revolucionarios. En este sentido, más que proponer conclusiones definitivas, el autor opta por sugerir posibles caminos interpretativos que ya han sido estudiados por la historiografía o bien otros que deben ser comprobados en estudios más detallados y específicos. Precisamente por contravenir esta tendencia, resulta llamativa la decisión y firmeza con la que el autor señala que la implementación de las Reformas Borbónicas no puede ser considerada como la causa más relevante en el proceso revolucionario independentista de Hispanoamérica. Klooster sustenta su afirmación destacando la fortaleza que exhibió la posición realista tanto en México como en Perú, dos de las regiones más afectadas por las Reformas (p. 156). Si bien concordamos en que las causas del movimiento independentista fueron múltiples y que las consecuencias de la puesta en práctica de las Reformas Borbónicas solo pueden ser consideradas como un factor más en el proceso independentista, resulta cuestionable negar o minimizar la importancia que el afán reformista Borbón tuvo en sus dominios americanos y su posterior implicancia en el proceso revolucionario, mucho más aun considerando las distintas realidades locales existentes en América. Un análisis más detallado o bien una conveniente matización respecto a este punto habrían resultado clarificadoras y de mucha mayor precisión.

Con todo, el esfuerzo de síntesis de Klooster es altamente significativo; su libro se constituye en una contribución valiosa tanto para el estudio empírico del periodo como desde un punto de vista metodológico. Teniendo presente que una de las principales dificultades de la utilización del método comparativo en historiografía radica en identificar procesos similares que a pesar de ser diferentes permitan su comparación sin caer en simplificaciones o reduccionismos, el autor construye una narración sólida y comprehensiva, erudita y al mismo tiempo accesible al lector. El mundo atlántico, entendido más como un espacio de interacción apto para el intercambio y la transferencia de ideas que como una barrera o límite geográfico, se constituye en este caso en un marco interpretativo apropiado para el estudio de un periodo tan turbulento como decisivo para la conformación del mundo occidental contemporáneo. 